\title{
Parâmetros físico-químicos de qualidade do medicamento genérico hidroclorotiazida em relação ao medicamento de referência Clorana ${ }^{\circledR}$
}

\author{
Physicochemical quality parameters of the generic drug hydrochlorothiazide in relation to the \\ reference drug Clorana ${ }^{\circledR}$ \\ Parámetros de calidad fisicoquímica del fármaco genérico hidroclorotiazida en relación con el \\ fármaco de referencia Clorana ${ }^{\circledR}$
}

\section{Resumo}

Este estudo possuiu o objetivo de comparar os parâmetros físico-químicos de qualidade do medicamento genérico hidroclorotiazida $25 \mathrm{mg}$ em relação ao medicamento de referência Clorana ${ }^{\circledR}$. Foram realizados os seguintes testes: determinação de peso médio, identificação, dureza, friabilidade, desintegração, dissolução e doseamento. Todos os testes apresentaram resultados satisfatórios. Na determinação do peso médio, os resultados obtidos para os dois medicamentos apresentaram pouca variação. No teste de identificação, as leituras das amostras estavam em concordância com o padrão. $\mathrm{O}$ teste de dureza foi informativo. A resistência ao atrito e ao impacto dos comprimidos estava dentro dos parâmetros, sendo assim a friabilidade foi satisfatória. Os comprimidos do hidroclorotiazida se desintegraram em um tempo maior que os do Clorana ${ }^{\circledR}$, mas dentro do estabelecido. Ambos os medicamentos foram dissolvidos dentro do tempo preciso. No teste de doseamento, o teor obtido estava dentro das conformidades. Tendo em vista os resultados dos testes dos ensaios físico-químicos, o estudo comprovou que os medicamentos estão dentro dos parâmetros de qualidade e certificou a segurança em termos físico-químicos da utilização do medicamento genérico testado no tratamento da Hipertensão Arterial Sistêmica.

Palavras-chaves: Hidroclorotiazida; Hipertensão; Medicamentos genéricos; Medicamentos de referência.

\footnotetext{
Abstract

This study aimed to compare the physical-chemical parameters of quality of the generic drug hydrochlorothiazide 25 $\mathrm{mg}$ in relation to the reference drug Clorana ${ }^{\circledR}$. The following tests were performed: determination of average weight, identification, hardness, friability, disintegration, dissolution and dosing. All tests showed satisfactory results. In determining the average weight, the results obtained for both drugs showed little variation. In the identification test,
} 
the sample readings were in agreement with the standard. The hardness test was informative. The resistance to friction and impact of the tablets was within the parameters, so the friability was satisfactory. The hydrochlorothiazide tablets disintegrated in a longer time than those of Chlorana ${ }^{\circledR}$, but within the established. Both drugs were dissolved within the precise time. In the dosing test, the content obtained was within the conformities. In view of the results of the tests of the physical-chemical tests, the study proved that the drugs are within the quality parameters and certified the safety in physical-chemical terms of the use of the generic drug tested in the treatment of Systemic Arterial Hypertension.

Keywords: Drugs, Generic; Hydrochlorothiazide; Hypertension; Reference drugs.

\section{Resumen}

Este estudio buscó comparar los parámetros de calidad fisicoquímica del fármaco genérico hidroclorotiazida 25 mg en relación al fármaco de referencia Clorana ${ }^{\circledR}$. Se realizaron las siguientes pruebas: determinación de peso medio, identificación, dureza, friabilidad, desintegración, disolución y dosificación. Todas las pruebas arrojaron resultados satisfactorios. Al determinar el peso promedio, los resultados obtenidos para los dos fármacos mostraron poca variación. En la prueba de identificación, las lecturas de la muestra coincidieron con el estándar. La prueba de dureza fue informativa. La resistencia a la fricción y al impacto de las tabletas estuvo dentro de los parámetros, por lo que la friabilidad fue satisfactoria. Las tabletas de hidroclorotiazida se desintegraron en más tiempo que las de Clorana®, pero dentro de los límites establecidos. Ambos fármacos se disolvieron en el tiempo preciso. En la prueba de dosificación, el contenido obtenido estuvo dentro del cumplimiento. A la vista de los resultados de las pruebas de los ensayos fisicoquímicos, el estudio demostró que los fármacos se encuentran dentro de los parámetros de calidad y certificó la seguridad en términos físico-químicos del uso del fármaco genérico testado en el tratamiento de la Hipertensión Arterial Sistémica.

Palabras clave: Hidroclorotiazida; Hipertensión; Medicamentos genéricos; Medicamentos de referencia.

\section{Introdução}

Os medicamentos genéricos foram registrados no ano de 1999, pela Lei n 9.787/99, e devem ser intercambiáveis com o medicamento de referência. Portanto, para sua comercialização, devem ser realizados testes para comprovação de sua eficácia terapêutica, que são as análises de equivalência e bioequivalência farmacêutica (Bertoldi, et al., 2016). Para comparar suas características físico-químicas e biológicas, são realizados testes que avaliem sua durabilidade, densidade, doseamento, friabilidade, entre outros, e é imprescindível que a qualidade do medicamento genérico seja equivalente à do medicamento de referência (Barata-Silva, et al., 2017). Segundo Lombardo e Eserian (2017), é necessário que o laboratório garanta a eficácia e a segurança dos medicamentos por meio de testes que avaliem a sua qualidade, uma vez que os mesmos são utilizados por pessoas que se encontram vulneráveis e que necessitam da resolução dos seus problemas de saúde através da farmacoterapia.

Os medicamentos genéricos foram lançados com o preço em média de $40 \%$ inferior aos dos medicamentos de referência e após quatro anos de lançamento dos medicamentos genéricos houve um aumento na diferença de preço entre estes, segundo o estudo conduzido por Vieira e Zuchi (2006). Apesar de muitas pessoas optarem pelo medicamento genérico, devido ao seu baixo preço, esses também geram muita desconfiança em alguns usuários. As incertezas são inúmeras, tais como, a confiabilidade em relação ao princípio ativo, ao efeito farmacológico, orientação de profissionais para fazer uso somente de medicamentos de referência, entre outras (Lira, et al., 2014). No entanto, a Agência Nacional de Vigilância Sanitária (ANVISA) assegura a qualidade desses medicamentos e garante a segurança na intercambialidade entre o medicamento genérico e o medicamento de referência (Sousa, Mesquita \& Lara, 2013).

A Hipertensão Arterial Sistêmica (HAS) é uma doença crônica que afeta o mundo todo e é caracterizada pelo aumento dos níveis pressóricos acima de 140/90 mmHg. Está associada frequentemente a alterações funcionais e/ou estruturais graves dos órgãos alvos do corpo humano, como: coração, encéfalo, rins e vasos sanguíneos e a alterações metabólicas, as quais podem aumentar o risco de problemas cardiovasculares. Os fatores de risco mais comuns para o surgimento da doença são obesidade, estresse, sedentarismo, maus hábitos alimentares e com alta ingestão de sódio, além de hereditariedade e idade (Magrini \& Martini, 2012; Sociedade Brasileira de Hipertensão, 2021). A HAS não tem cura, mas pode ser controlada por meio de medicamentos e o tratamento deve ser seguido corretamente. Além disso, é importante que o medicamento atue de 
forma adequada no organismo e atinja a efetividade terapêutica esperada no paciente (Sociedade Brasileira de Hipertensão, 2021).

De acordo com o Programa Nacional de Uso Racional de Medicamentos (PNAUM), a maioria dos medicamentos genéricos que são utilizados para o controle da pressão arterial, são adquiridos no Sistema Único de Saúde (SUS). Contudo, esses medicamentos também podem ser obtidos em farmácias privadas, pela farmácia popular e por outras fontes (como instituições de caridade, igrejas e asilos). No Brasil, a hidroclorotiazida é o medicamento anti-hipertensivo mais utilizado, seguida pelo losartana e captopril (Bertoldi, et al., 2016).

As diretrizes da HAS recomendam o uso dos medicamentos diuréticos tiazídicos, como a hidroclorotiazida, no início do tratamento ou como terapia combinada na progressão da doença. A hidroclorotiazida apresenta em sua estrutura um grupo sulfonamida, que causa a inibição da atividade anidrase carbônica e estima-se que essa inibição possa estar associada à menor contratilidade vascular. Em concentrações plasmáticas baixas, a hidroclorotiazida consegue seu efeito diurético, pois é concentrada nos rins e secretada no lúmen tubular, inibe o co-transportador de cloreto de sódio na membrana luminal do túbulo contorcido distal da alça ascendente de Henle, causando então uma pequena diurese. Adicionalmente, o medicamento aumenta a secreção de íons de potássio juntamente com íons de hidrogênio, promovendo assim uma grande reabsorção de cálcio. A ação da hidroclorotiazida se dá cerca de duas horas após o uso e seu pico pode ser atingido entre quatro a seis horas após a administração. A duração do efeito do medicamento é de 12 horas (Cooney, Milfred-LaForest, \& Rahman, 2015).

Através da experiência em campo de estágio, foi possível observar a preferência da população por medicamentos de referência em relação ao medicamento genérico, deste modo, e devido à importância da efetividade do medicamento no tratamento da HAS, que é uma doença crônica e necessita do uso contínuo do mesmo, e considerando a importância da ausência de alteração na formulação do medicamento genérico, quando comparado ao de referência, o presente estudo teve como objetivo comparar o medicamento genérico hidroclorotiazida $25 \mathrm{mg}$ de um determinado laboratório, com o seu medicamento de referência Clorana ${ }^{\circledR}$, por meio de testes físico-químicos.

\section{Metodologia}

O presente trabalho utilizou uma abordagem quantitativa. Nesta abordagem, são coletados dados quantitativos ou numéricos por meio do uso de medições de grandezas e podem ser analisados por meio de técnicas matemáticas (Pereira, et al., 2018). A metodologia utilizada para os ensaios que avaliaram a qualidade do medicamento genérico hidroclorotiazida, está em concordância com a Farmacopeia Brasileira, $6^{a}$ edição, (2019). Para a realização deste trabalho, foram realizados testes de determinação de peso, identificação, dureza, friabilidade, desintegração, dissolução e doseamento. Os testes foram conduzidos em um laboratório de uma indústria farmacêutica.

\section{Amostra}

As amostras do medicamento genérico hidroclorotiazida $25 \mathrm{mg}$ de um determinado laboratório na forma de comprimido e as amostras do medicamento de referência Clorana ${ }^{\circledR} 25 \mathrm{mg}$, foram adquiridas em uma drogaria de um município localizado na região do Centro Oeste do estado de Minas Gerais, no qual foi escolhida por meio de um sorteio. O medicamento hidroclorotiazida e o laboratório fabricante foram escolhidos por ser o medicamento mais utilizado no tratamento da HAS e por ser o laboratório mais vendido na drogaria em questão, além disso, a baixa quantidade de amostragem foi devido à intenção de não interferir na rotina diária do laboratório da empresa parceira durante a realização dos testes.

Em todos os testes, procedeu-se conforme descrito na Farmacopeia Brasileira, $6^{a}$ edição, (2019). Os reagentes utilizados mantinham-se dentro dos padrões analíticos especificados, com o grau de pureza aceitável. A água utilizada foi destilada e as vidrarias e equipamentos estavam devidamente calibrados. 


\section{Identificação}

Pesou-se e pulverizou-se os comprimidos do medicamento genérico hidroclorotiazida. Em seguida, transferiu-se 10 $\mathrm{mg}$ da amostra do medicamento para um béquer de $100 \mathrm{ml}$ contendo $20 \mathrm{ml}$ de acetona. Filtrou-se e em seguida a amostra do medicamento passou por aquecimento até a secura. Um resíduo se formou e foi separado para aguardar o resfriamento. Em um grau de Ágata pesou-se $300 \mathrm{mg}$ de brometo de potássio e posteriormente acrescentou-se $3 \mathrm{mg}$ da amostra do medicamento genérico hidroclorotiazida previamente pulverizada. Logo, abrandou-se a amostra do medicamento juntamente com o brometo de potássio e realizou-se a leitura no espectrofotômetro infravermelho Rertin Elmer, modelo Spectrum 400, nos comprimentos de onda de $400 \mathrm{~nm}$ a $4000 \mathrm{~nm}$.

O mesmo procedimento foi realizado com o padrão e com a amostra do medicamento de referência Clorana®. O teste de identificação foi um método desenvolvido e validado pela indústria farmacêutica em que foram realizadas as análises.

\section{Determinação de peso médio}

Pesou-se individualmente em uma balança analítica Adventurer OHAUS, 20 comprimidos de cada amostra. Somou-se o valor de cada peso e dividiu-se pela quantidade de comprimidos e, desta forma, determinou-se o peso médio. As amostras não devem apresentar variações, superiores ou inferiores, a 7,5\%, cumprindo, portanto, com os requisitos especificados pela farmacopeia ${ }^{9}$. O limite máximo a ser tolerado, são duas unidades fora dos limites especificados em relação ao peso médio, porém, nenhuma poderá estar acima ou abaixo do dobro das porcentagens indicadas.

\section{Teste de dureza}

No teste de dureza, 10 comprimidos do medicamento genérico de hidroclorotiazida e 10 comprimidos do medicamento de referência Clorana ${ }^{\circledR}$ foram submetidos à ação do equipamento durômetro Erweka, modelo TDH 220, que mediu a força aplicada diametralmente, necessária para esmagá-los. A força foi medida em newtons (N). Eliminou-se qualquer resíduo superficial antes de cada determinação. Os comprimidos foram testados individualmente, obedecendo sempre à mesma orientação (considerou-se a forma, presença de ranhura e gravação). O resultado foi expresso como a média dos valores obtidos nas determinações e foi informativo.

\section{Teste de friabilidade}

Pesou-se com exatidão 20 comprimidos do medicamento genérico hidroclorotiazida e 20 comprimidos do medicamento de referência Clorana ${ }^{\circledR}$, os quais foram submetidos à ação do aparelho friabilômetro Ethik, modelo 300 (25 RPM por 4 minutos) e retirados depois de efetuadas 100 rotações. Após o teste, foram removidos todos os resíduos de pó da superfície dos comprimidos e pesou-se novamente.

Para identificar a quantidade de pó que foi perdida durante o processo, foi utilizada a seguinte fórmula: (P1P2)x100/P1, em que P1 significa peso inicial e P2 peso final. De acordo com a Farmacopeia Brasileira 6a edição, (2019) a quantidade de perda de pó permitida não poderá ser superior a $1,5 \%$.

\section{Testes de desintegração}

Foram submetidas à ação do equipamento desintegrador Ethik, 6 unidades do medicamento genérico hidroclorotiazida e 6 unidades do medicamento de referência Clorana®, no tempo máximo de 30 minutos na temperatura de $37^{\circ} \mathrm{C}$. A desintegração foi definida para os fins desse teste, como o estado no qual nenhum resíduo das unidades testadas permanecesse na tela metálica do aparelho de desintegração. 


\section{Teste de dissolução}

Separou-se 6 cubas de $1000 \mathrm{~mL}$ e 6 cestos, adicionou-se em cada cuba $900 \mathrm{~mL}$ do meio de dissolução utilizado, ácido clorídrico $0,1 \mathrm{M}$ e esperou-se atingir a temperatura de $37^{\circ} \mathrm{C}$ no dissolutor Distek, modelo 6100 . Os comprimidos foram pesados e adicionados nos cestos. Em cada cesto havia 1 comprimido do medicamento genérico hidroclorotiazida. Os cestos moviamse a 100 RPM durante 30 minutos. Após esse período, retirou-se uma alíquota do meio de dissolução, filtrou-se e coletou-se 1 $\mathrm{mL}$ de cada filtrado e transferiu-se para um balão volumétrico de $25 \mathrm{~mL}$, utilizando-se então seis balões volumétricos, os quais foram completados com ácido clorídrico 0,1 M. O mesmo procedimento foi realizado com a amostra do medicamento de referência Clorana®.

Para o preparo do padrão, utilizou-se $10 \mathrm{mg}$ do padrão e transferiu-se para o balão volumétrico de $100 \mathrm{~mL}$. Adicionou-se ácido clorídrico 0,1 M completando até o menisco, em seguida solubilizou-se no ultrassom e depois coletou-se 1 $\mathrm{mL}$ dessa solução com uma pipeta. Transferiu-se para outro balão volumétrico de $100 \mathrm{~mL}$ e completou-se até o menisco com ácido clorídrico $0,1 \mathrm{M}$.

Mediu-se as absorbâncias das soluções em 272 nm, utilizando o mesmo solvente para ajuste do zero. Calculou-se a quantidade de hidroclorotiazida dissolvida no meio, comparando as leituras obtidas com as do padrão de hidroclorotiazida. Logo após, foi realizada a leitura no espectrofotômetro de UV Agilent, modelo 8453, onde a tolerância deveria ser no mínimo $\mathrm{Q}=60+5 \%$ da quantidade declarada de hidroclorotiazida.

\section{Teste de doseamento}

Pulverizou-se 20 comprimidos do medicamento genérico hidroclorotiazida e 20 comprimidos do medicamento de referência Clorana®. Pesou-se a quantidade do pó equivalente a $30 \mathrm{mg}$ de cada medicamento e do padrão do genérico hidroclorotiazida. Utilizou-se três balões volumétricos de $100 \mathrm{~mL}$ e transferiu-se cada quantidade para um balão volumétrico. Completou-se até o menisco com hidróxido de sódio $0,1 \mathrm{M}$ e deixou durante 20 minutos no ultrassom para solubilizar.

Após solubilizado, recolheu-se de cada balão volumétrico uma alíquota de $5 \mathrm{~mL}$ e utilizando-se outros três balões volumétricos de $100 \mathrm{~mL}$, transferiu-se a alíquota para cada um dos balões. Completou-se até o menisco com água e homogeneizou-se. As absorbâncias das soluções foram medidas em $273 \mathrm{~nm}$, utilizando água para ajuste do zero. Os resultados foram disponibilizados após as leituras realizadas pelo equipamento espectrofotômetro de UV Agilent, modelo 8453, e devem estar entre $93 \%$ a $107 \%$.

\section{Resultados e Discussão}

\section{Identificação}

$\mathrm{O}$ teste de identificação realizado com a amostra do medicamento genérico hidroclorotiazida e com o medicamento de referência Clorana ${ }^{\circledR}$ tiveram suas leituras em comprimento de ondas semelhantes ao padrão, indicando que os medicamentos estão conforme as especificações pré-estabelecidas. As Figuras 1 e 2 representam os resultados das leituras realizadas no espectrofotômetro infravermelho do medicamento genérico hidroclorotiazida e do medicamento de referência Clorana ${ }^{\circledR}$, respectivamente. 
Figura 1: Leitura realizada no espectrofotômetro infravermelho do medicamento genérico hidroclorotiazida.

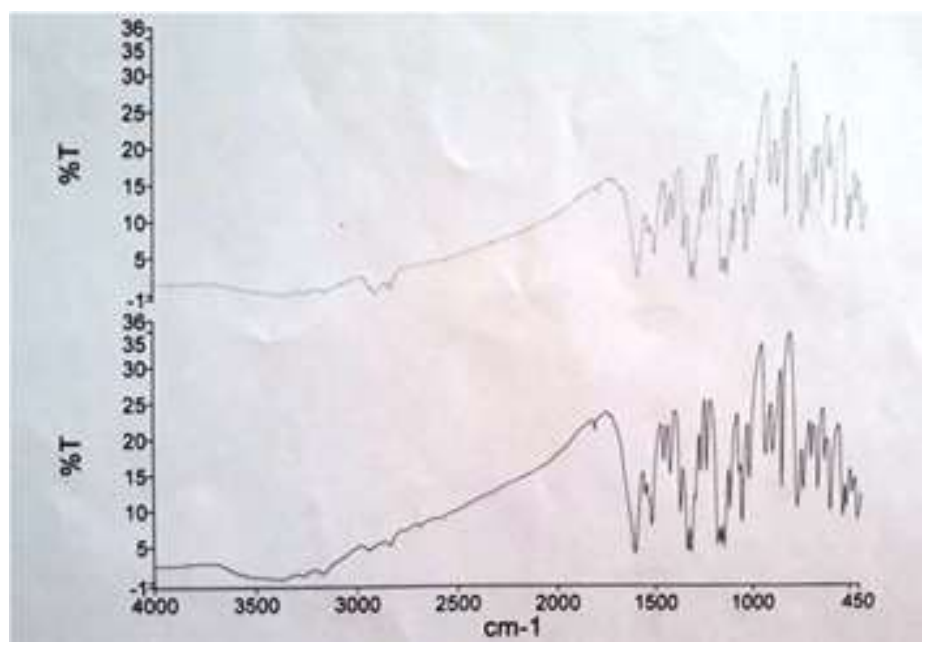

Legenda: \%T: Precipitância.

Fonte: autores.

Figura 2: Leitura realizada no espectrofotômetro infravermelho do medicamento de referência Clorana®.

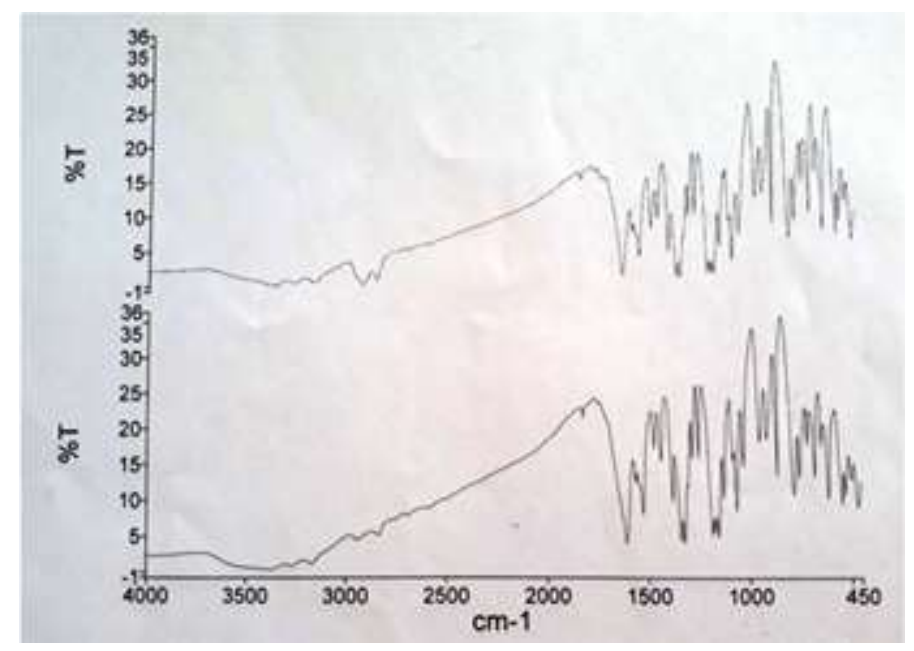

Legenda: \%T: Precipitância.

Fonte: autores.

O teste de identificação não é comumente realizado e por isso não possui especificação na Farmacopeia Brasileira, $6^{\mathrm{a}}$ edição, (2019). Os resultados de correlação devem estar acima de 0,95\%. Através desse teste, foi possível comparar as amostras com o padrão de hidroclorotiazida, e assim avaliar se as quantidades do princípio ativo e dos excipientes contidos nos medicamentos estavam dentro dos limites especificados. Observou-se uma pequena variação na leitura dos comprimentos de onda, resultantes do teste conduzido no espectrofotômetro de infravermelho. Contudo, essa variação pode ser explicada pelo fato do padrão ter em sua composição apenas o princípio ativo hidroclorotiazida, enquanto que nas amostras, além do princípio ativo existem excipientes em sua formulação.

\section{Determinação de peso médio}

O peso médio do medicamento genérico hidroclorotiazida foi 120,5 mg e o peso médio do medicamento de referência Clorana ${ }^{\circledR} 109,3$ mg. O desvio padrão e o desvio padrão relativo do medicamento hidroclorotiazida foi 2,649 e 2,199, e do medicamento Clorana ${ }^{\circledR}$ foi 1,099 e 1,006, respectivamente (Figuras 3 e 4). 
Figura 3: Variações de peso médio do medicamento genérico hidroclorotiazida.

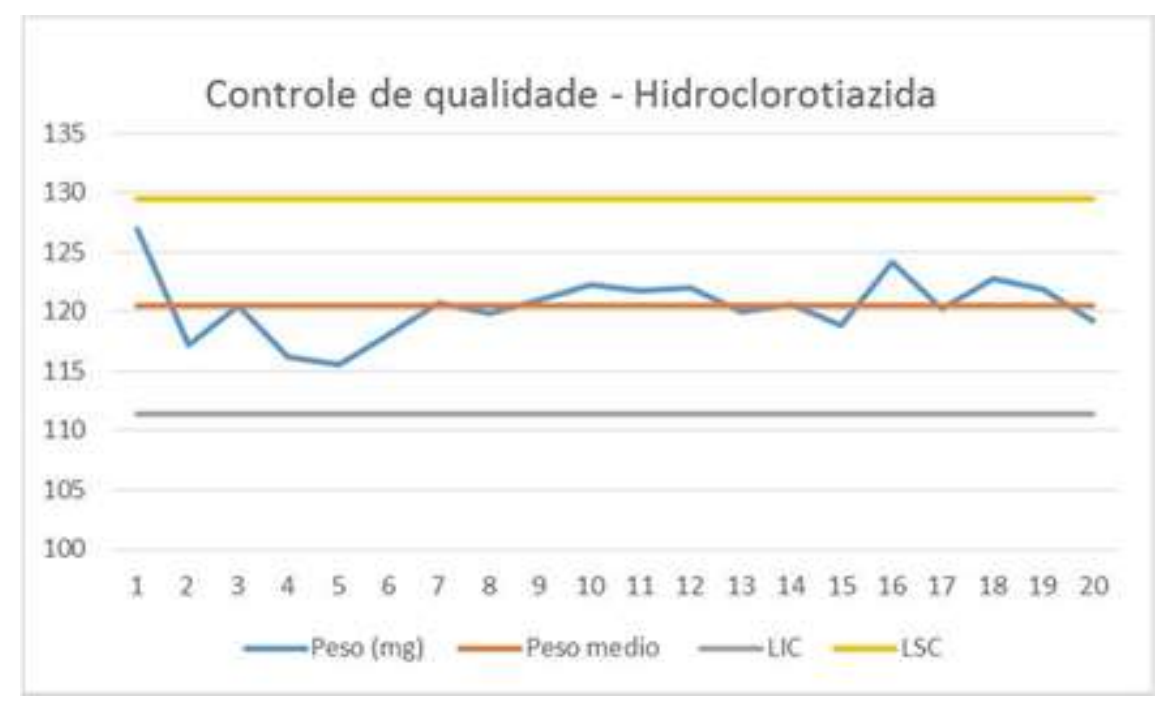

Legenda: LIC: Limite de concentração inferior; LSC: Limite superior de concentração. Fonte: autores.

Figura 4: Variações de peso médio do medicamento de referência Clorana®.

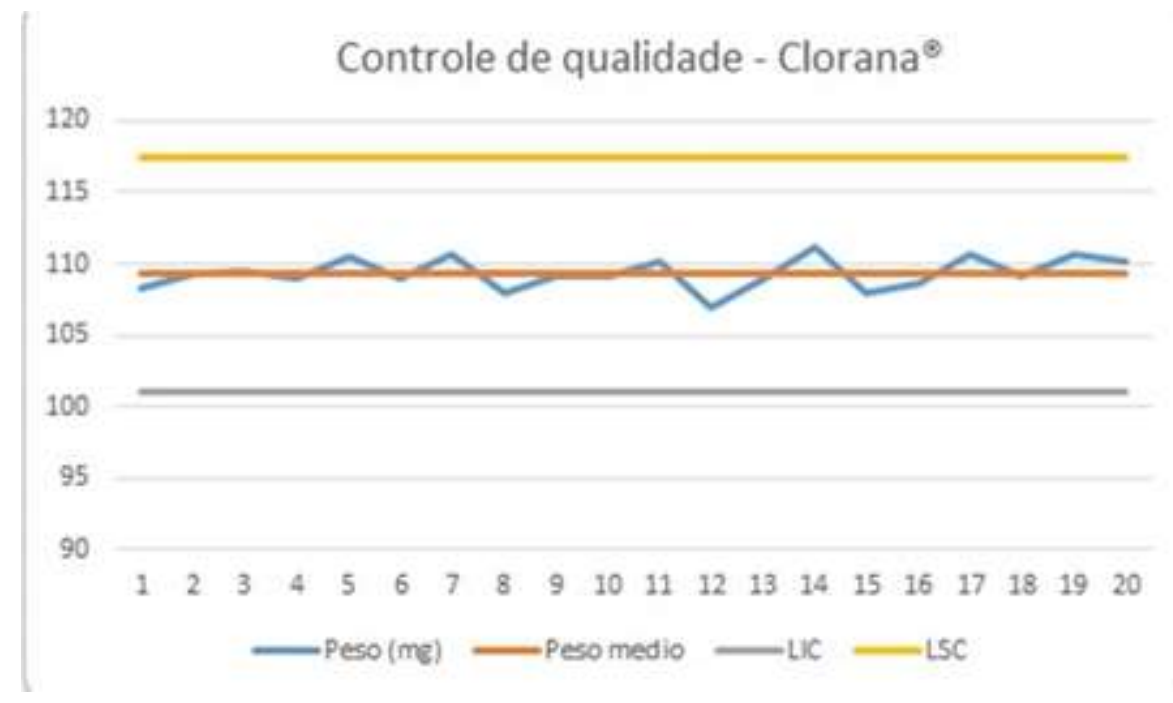

Legenda: LIC: Limite de concentração inferior; LSC: Limite superior de concentração. Fonte: autores.

A uniformidade dos pesos entre os comprimidos é dada através do ensaio de determinação do peso médio. A realização deste teste é importante para garantir a quantidade adequada de princípio ativo, a qual pode influenciar diretamente na efetividade e na segurança do medicamento (Gomes, et al., 2020). Ao analisar os resultados obtidos, foi possível observar que o medicamento genérico hidroclorotiazida apresentou maior variação no peso de cada comprimido quando comparado ao medicamento de referência Clorana®, o qual manteve os pesos dos comprimidos mais próximos da média. No entanto, os dois medicamentos apresentaram resultados dentro dos limites de concentração. Resultado semelhante foi obtido no estudo de Mariano' et al., (2015), onde foram analisados comprimidos contendo dipirona sódica $500 \mathrm{mg}$ de três marcas similares distintas. Assim como no estudo em foco, utilizaram 20 comprimidos de cada produto, analisando a qualidade dos medicamentos e os dados mostraram que pouca diferença foi observada na distribuição de peso entre os comprimidos e nenhum deles esteve fora do limite especificado. 


\section{Teste de dureza}

Realizou-se a leitura de 10 comprimidos em um equipamento calibrado com a força $(\mathrm{N})$. De acordo com a Farmacopeia Brasileira, $6^{a}$ edição, (2019), não são estabelecidos parâmetros para esse teste, sendo assim, o resultado foi informativo.

$\mathrm{Na}$ Tabela 1, encontram-se os resultados da amostra do medicamento genérico hidroclorotiazida e do medicamento de referência Clorana®.

Tabela 1: Resultados da dureza do medicamento genérico hidroclorotiazida e do medicamento de referência Clorana®.

\begin{tabular}{|c|c|c|}
\hline Comprimidos & Clorana ${ }^{\circledR}$ & Hidroclorotiazida \\
\hline 01 & 44,6 & 75,8 \\
\hline 02 & 38,2 & 72,6 \\
\hline 03 & 45,2 & 54,2 \\
\hline 04 & 41,4 & 65,0 \\
\hline 05 & 52,9 & 62,4 \\
\hline 06 & 50,3 & 66,3 \\
\hline 07 & 43,3 & 59,3 \\
\hline 08 & 49,7 & 69,4 \\
\hline 09 & 48,4 & 60,5 \\
\hline 10 & 51,6 & 65,6 \\
\hline Dureza média (N) & 46,6 & 65,1 \\
\hline
\end{tabular}

Fonte: autores.

\section{Teste de friabilidade}

Os cálculos realizados para o teste de friabilidade foram:

- $\quad$ Hidroclorotiazida: $2,4140-2,4123 \times 100 / 2,4140=0,07 \%$

- $\quad$ Clorana®: $2,1934-2,1913$ x $100 / 2,1934=0,10 \%$ e estão representandos na Tabela 2. 
Tabela 2: Resultados da friabilidade do medicamento genérico hidroclorotiazida e do medicamento de referência Clorana®.

\begin{tabular}{ccc}
\hline & Hidroclorotiazida & Clorana $^{\circledR}$ \\
\hline Peso inicial & $2,4140 \mathrm{~g}$ & $2,1934 \mathrm{~g}$ \\
Peso final & $2,4123 \mathrm{~g}$ & $2,1913 \mathrm{~g}$ \\
Variação & $0,0017 \mathrm{~g}$ & $0,0021 \mathrm{~g}$ \\
Perda(\%) & $0,07 \%$ & $0,10 \%$ \\
& & \\
\hline
\end{tabular}

Fonte: autores.

Em relação aos testes de dureza e friabilidade, estes possuem como objetivo avaliar a adequada resistência dos comprimidos ao atrito e ao impacto e podem predizer a desintegração, uma vez que essas análises garantem a integridade física do medicamento no momento da dispensação e da administração (Ferreira, et al., 2013). O teste de dureza avalia a força que é inserida sobre o comprimido para determinar a resistência ao esmagamento (Simch, 2013). Já o teste de friabilidade avalia a resistência mecânica do comprimido ao desgaste, em razão de que os comprimidos que tendem a perder pó, podem apresentar variação de peso ou de uniformidade (Lima et al., 2006).

Os resultados do presente estudo mostraram que a amostra do medicamento genérico hidroclorotiazida apresentou a dureza média de 65,1 (N), enquanto a amostra do medicamento de referência Clorana ${ }^{\circledR}$ apresentou a dureza média de 46,6 (N). Observa-se uma variação nos valores relacionados à dureza, mostrando que os comprimidos do medicamento de referência Clorana ${ }^{\circledR}$ possuem maior sensibilidade em relação ao medicamento genérico hidroclorotiazida, podendo ter mais facilidade de quebra, e isso pode estar relacionado com os excipientes utilizados em sua formulação. Ainda assim, os medicamentos estão aptos para o consumo. Já no teste de friabilidade, a perda de pó do medicamento genérico hidroclorotiazida foi $0,07 \%$ e a perda de pó do medicamento de referência Clorana ${ }^{\circledR}$ foi $0,10 \%$. Esse resultado foi contrário ao obtido por Gomes, et al., (2020), uma vez que os autores observaram uma maior perda no medicamento genérico, quando comparado ao de referência e a reprovação do medicamento genérico no teste de dureza. De acordo com o obtido no presente estudo, pode-se dizer que os medicamentos são resistentes ao atrito e ao impacto e que a perda de pó foi menor que a preconizada pela Farmacopeia Brasileira, $6^{\mathrm{a}}$ edição, (2019), assim os parâmetros como desintegração e dissolução não foram prejudicados.

\section{Teste de desintegração}

Após o processo, todos os comprimidos se desintegraram totalmente e os resultados mostraram que o medicamento genérico hidroclorotiazida se desintegrou em maior tempo (3 minutos e 5 segundos) que o medicamento de referência Clorana ${ }^{\circledR}(2$ minutos e 19 segundos), o que poderia indicar que sua liberação no organismo seria mais lenta. Comparando com o trabalho realizado por Ferreira' et al., (2013) observou-se semelhança nos resultados de dureza, friabilidade e desintegração, podendo ainda confirmar a observação feita pelos autores, em que os comprimidos que apresentaram menor tempo de desintegração também apresentaram menor dureza e maior friabilidade. Essa relação é coerente com o padrão de resistência mecânica dos comprimidos, mas não pode ser definida como regra (Ferreira, et al., 2013). 


\section{Teste de dissolução}

O teste de dissolução apresentou resultados satisfatórios, já que os comprimidos analisados foram dissolvidos em um tempo inferior a 30 minutos. Após o teste, observou-se que o medicamento genérico hidroclorotiazida e o medicamento de referência Clorana ${ }^{\circledR}$, apresentaram o resultado de acordo com o critério de aceitação, igual ou maior que $\mathrm{Q}+5 \%(\mathrm{Q}=60+5 \%)$ (Figura 5).

Figura 5: Resultados da leitura realizada no espectrofotômetro UV para o medicamento genérico hidroclorotiazida e o medicamento de referência Clorana®.

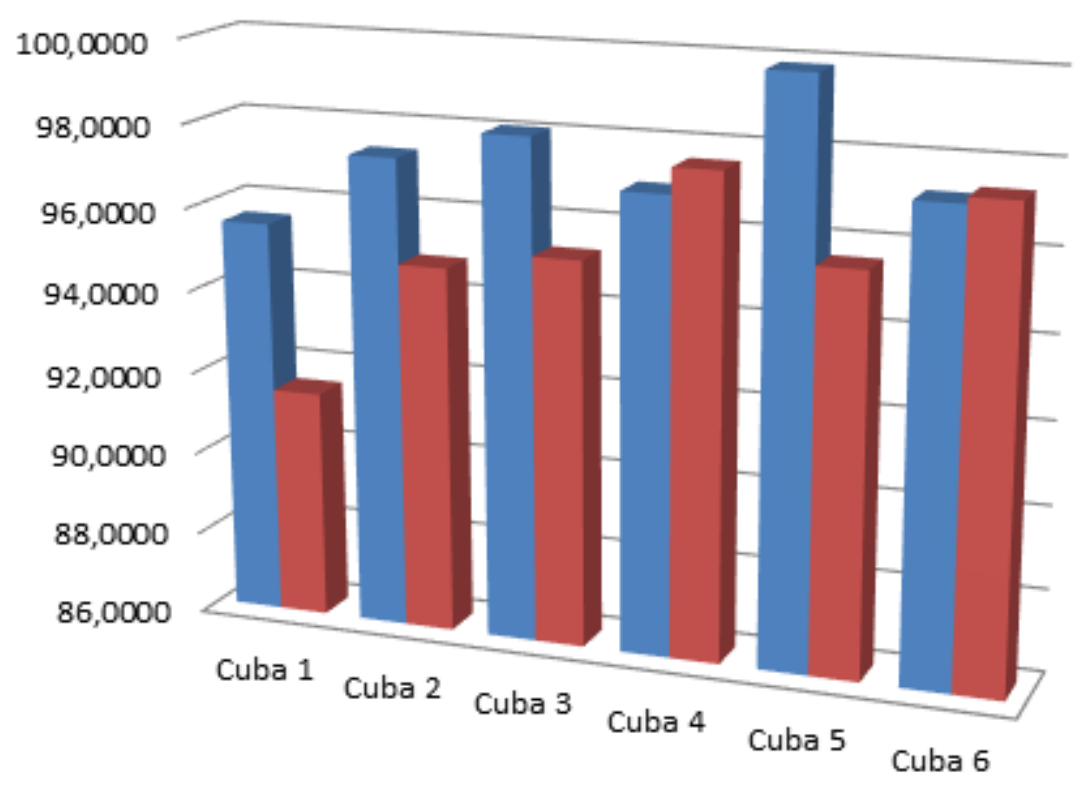

n Clorana $^{\ominus}$ Hidroclorotiazida

Fonte: autores.

O teste de dissolução avalia a quantidade de princípio ativo no meio de dissolução, e qualquer alteração na sua taxa pode comprometer a biodisponibilidade do fármaco (Lima et al., 2006). Em semelhança com o estudo de Schmalz et al., (2010), que também analisou o medicamento hidroclorotiazida através de testes fisico-químicos, as amostras foram aprovadas com valores dentro do preconizado no tempo especificado. Porém, entre as amostras analisadas houve variação de quantidade de princípio ativo dissolvido no meio de dissolução, assim como o medicamento de referência Clorana ${ }^{\circledR}$ apresentou uma quantidade maior de princípio ativo disponível no meio de dissolução em ambos os estudos.

\section{Teste de doseamento}

O teste de doseamento foi realizado por espectrofotômetria de absorção do UV e os resultados mostraram-se satisfatórios, uma vez que ambos os medicamentos, genérico hidroclorotiazida e referência Clorana ${ }^{\circledR}$, apresentaram-se dentro da faixa de especificação.

Na Tabela 3, encontram-se os resultados da leitura realizada no espectrofotômetro do padrão do hidroclorotiazida, do medicamento genérico hidroclorotiazida e do medicamento de referência Clorana®. 
Tabela 3: Resultados do doseamento do padrão, medicamento genérico hidroclorotiazida e medicamento de referência Clorana ${ }^{\circledR}$.

\begin{tabular}{cc}
\hline Amostra & Teor (\%) \\
\hline Padrão & 100,18 \\
Referência & 102,09 \\
Genérico & 95,88 \\
\hline
\end{tabular}

Fonte: autores.

A média para o medicamento genérico hidroclorotiazida foi $95,88 \%$ e a média para o medicamento de referência Clorana ${ }^{\circledR}$ foi $102,09 \%$, mostrando então resultados satisfatórios, pois estiveram dentro da porcentagem estabelecida pela Farmacopeia Brasileira, $6^{\circ}$ edição, (2019), onde o teor deve estar entre 93\% a 107\%. De acordo com Rigobello' et al., (2013), se o medicamento apresentar teor abaixo do especificado, ele pode prejudicar a efetividade do tratamento farmacoterapêutico, e caso apresente teor acima, pode apresentar efeitos adversos e toxicidade. Os valores obtidos no presente estudo mostraram que na produção dos comprimidos não houve separação dos pós e obteve-se uniformidade do princípio ativo e dos excipientes no momento da mistura, indicando assim baixa variação de peso médio dos comprimidos analisados.

De acordo com os resultados obtidos, pode-se observar que as amostras dos medicamentos testados, genérico hidroclorotiazida e referência Clorana ${ }^{\circledR}$, apresentaram os resultados satisfatórios, pois ambos estavam dentro das especificações da Farmacopeia em todos os testes. Uma revisão de literatura realizada no Brasil, concluiu que a grande maioria de medicamentos genéricos e similares vendidos no país possuem o mesmo perfil de qualidade dos de referência (Santos, et al., 2020). Apesar do ceticismo de alguns pacientes, bem como de profissionais de saúde, os quais alegam a inexistência de qualidade dos medicamentos genéricos, frente aos de referência (White, 2020) os ensaios físico-químicos realizados nesse estudo comprovaram a qualidade do fármaco, sendo possível certificar a segurança dos medicamentos em relação a estes ensaios.

Algumas limitações devem ser consideradas em relação ao presente estudo, como a quantidade de lotes e amostras analisadas, referindo-se a uma pequena quantidade de amostragens. Além disso, teve-se a delimitação para a execução de testes, como exemplo, cromatografia líquida de alta eficiência (HPLC), bioequivalência e equivalência farmacêutica. Contudo, o estudo agrega grande valor para a população, pois com sua realização foi possível observar que em relação aos parâmetros físico-químicos, da mesma forma que o medicamento de referência, o medicamento genérico testado apresentou resultados em conformidade com a legislação, o que mostra a sua qualidade.

\section{Conclusão}

Os resultados dos testes mostraram que o medicamento genérico hidroclorotiazida está dentro dos parâmetros físicoquímicos de qualidade, em comparação ao medicamento de referência Clorana®, pois apresentou os resultados dentro das especificações. Portanto, de acordo com os testes realizados o medicamento não apresenta alteração em sua formulação e está apto para o consumo e tratamento das HAS. No entanto, é importante que sejam realizadas novas pesquisas envolvendo tanto a realização de testes com outros laboratórios quanto com medicamentos similares para que os dados possam ser generalizados.

\section{Referências}

Barata-Silva, C., et al. (2017) Desafios ao controle da qualidade de medicamentos no Brasil, Cadernos Saúde Coletiva, 25(3), 362-370. 
Bertoldi, A. D., et al. (2016) Use of generic medicines by the Brazilian population: An evaluation of PNAUM 2014. Revista de Saude Publica, 50(supl 2),111 .

Cooney, D., Milfred-LaForest, S., \& Rahman, M. (2015) Diuretics for hypertension: Hydrochlorothiazide or chlorthalidone? Cleveland Clinic journal of medicine, 82(8), 527-533.

Farmacopeia brasileira. Agência Nacional de Vigilância Sanitária, (6º ed.): 2019. 952 a 957 p.

Ferreira, T. F., et al. (2013). Estudo comparativo da influência dos excipientes na qualidade de hidroclorotiazida 25 mg em medicamentos referência e genéricos. Revista de Ciencias Farmaceuticas Basica e Aplicada, 34(1), 63-68.

Gomes, N. D. B., et al. (2020). Avaliação da qualidade físico-química de comprimidos de hidroclorotiazida. Estudo comparativo entre medicamentos de referência, genérico e similar. JAPHAC, 7, 172-182.

Lima, A. C., et al. (2006). Força de compressão e umidade no perfil de dissolução da hidroclorotiazida. Acta Farmaceutica Bonaerense, 25(1), $104-107$.

Lira, C. A. B., et al. (2014). Knowledge, perceptions and use of generic drugs: a cross sectional study. Einstein (São Paulo, Brazil), 12(3), 267-273.

Lombardo, M., \& Eserian, J. K. (2017). A análise da qualidade de medicamentos e o papel do laboratório oficial no contexto da saúde pública. Rev. Adm. Saúde, 17(67).

Magrini, W., \& Martini, Gue (2011) Hipertensão arterial : principais fatores de risco modificáveis na estratégia saúde da família. Enfermeria Global, 11(26), 354-363.

Mariano, M. D. C., et al. (2015). Controle De Qualidade Físico-Químico De Comprimidos De Dipirona Sódica Adquiridos Em Drogarias De São Luis De Montes Belos (GO). Revista Faculdade Montes Belos (FMB), 8(1), 1-10.

Pereira, A. C., et al. (2018). Metodologia da pesquisa científica. (1 ${ }^{\text {a }}$ ed.) UAB/ NTE/ UFSM. Universide Federal de Santa Maria, Santa Maria, Rio Grande do Sul.

Rigobello, C., et al. (2013). Avaliação da qualidade e perfil de dissolução de comprimidos de cloridrato de propranolol. Acta Scientiarum - Health Sciences, $35(1), 85-90$.

Santos, T. S., et al. (2020). Avaliação da qualidade de medicamentos similar, genérico e referência vendidos no Brasil: uma revisão de literatura. Research, society and development, 9(7).

Schmalz, C., et al. (2010). Avaliação da qualidade de quatro especialidades farmacêuticas contendo hidroclorotiazida. Rev. Bras. Farm, 91(3), 126 -32.

Simch, F. H. (2013). Testes Aplicados Em Estudos De Equivalência Farmacêutica. Universidade do Paraná, Tecnologia em biotecnologia [Trabalho de conclusão de curso] p. 35.

Sociedade Brasileira de Hipertensão. (2021). Diretrizes brasileiras da hipertensão arterial - 2020. Arq Bra Cardiol., 116(3), 516-658.

Sousa, C. V., Mesquita, J. M. C., \& Lara, J. E. (2013) Análise da decisão de compra de medicamentos frente à existência de produtos substitutos: um estudo no município de Belo Horizonte, Brasil. Ciênc. saúde coletiva, 18(11), 3311-3320.

Vieira, F. S., \& Zucchi, P. (2006) Diferenças de preços entre medicamentos genéricos e de referência no Brasil. Revista de Saude Publica, 40(3), 444-449.

White, C. M. (2020). Generic drugs not as safe as FDA wants you to believe. Annals of pharmacotherapy, 54(3), 283-286. 